Original article

https://www.journal-imab-bg.org

\title{
TRIBOLOGICAL TESTS OF RESIN-BASED COM- POSITE MATERIALS: A DESIGN STUDY
}

\author{
Valeriya Aleksandrova ${ }^{1}$, Neshka Manchorova ${ }^{1}$, Svetlin Aleksandrov ${ }^{2}$ \\ 1) Department of Operative Dentistry and Endodontics, Faculty of Dental Medi- \\ cine, Medical University-Plovdiv, Bulgaria \\ 2) Department of Prosthetic Dentistry, Faculty of Dental Medicine, Medical \\ University-Plovdiv, Bulgaria.
}

\begin{abstract}
:
Objective: The objective of our research is to study the tribological behaviour of two types of commercially available resin-based composite materials.

Material and method: An original experimental model for tribological studies of dental materials in standard test conditions was applied. Two types of resin-based composite materials indicated for the treatment of dental caries in the distal area were used: a micro-hybrid resinbased composite material (Gradia Direct posterior); packable resin-based composite material (Filtek P60). Metal alloy (Duceralloy C) was used for positive control. Total 18 test samples ( $\mathrm{n}=9$ for each material) were subject to: micro scratch resistance test in $1 \mathrm{~N}, 5 \mathrm{~N}, 9 \mathrm{~N}$ mode; friction resistance "Ball-on-Flat" test at 120,000/240,000 cycles loaded on $50 \mathrm{~N}$.

Results: When the maximum load was applied, Gradia Direct posterior had higher values of scratch depths $(40,23 \mu \mathrm{m})$ than Filtek P60 $(25,13 \mu \mathrm{m})$. The micro-hybrid composite exhibited less wear resistance that decreased with increasing time and friction cycles $(13 \mu \mathrm{m}$ after 30 $\mathrm{min} / 120,000$ cycles; $18 \mu \mathrm{m}$ ether $60 \mathrm{~min} / 240,000$ cycles $)$. The examined surfaces of the test specimens were visualized by optical microscopy after micro scratch and friction test and by 3D profilometry of all tested samples after 240,000 wear cycles.

Conclusion: Results in this field might clarify the mechanisms of wear and provide additional information on the expected changes in the studied materials in clinical practice.
\end{abstract}

Keywords: dental tribology, original experimental model, "Ball-on-Flat" test, 3D profilometry.

\section{INTRODUCTION:}

The frequency of patients with parafunction in the world population has been increased. According to most literature sources, the prevalence of adults exhibiting some periods of bruxism ranges from $6 \%$ to $20 \%$ [1]. Most epidemiologic studies have shown that patients tend to be less prone to bruxism as they age [2].

It has been accepted that tooth wear is a clinical problem that is becoming increasingly important in ageing populations. More often, patients with both occlusal tooth wear and caries on posterior teeth need specific treatment decisions. The choice of biomaterial restoring distal carious lesions on wear teeth requires simulation of extreme masticatory forces in laboratory experiments before clinical application.

Examination of tribological properties of dental materials is a growing and rapidly expanding field. Tribology is the science explaining the mechanisms of friction, lubrication and wear of interacting surfaces that are in relative motion. Intensive research has been conducted to prove the significance and applicability of dental tribology for the selection of artiûcial dental materials for the treatment of carious lesions in the high-stress region [3].

The main problem involved in the dental application of resin-based composite materials is their inadequate resistance against wear when used as posterior composite restorations in extreme masticatory forces [2].

The objective of our research is to study the tribological behaviour of two types of commercially available resin-based composite materials.

\section{MATERIALS AND METHODS:}

An original experimental model for tribological studies of dental materials in standard test conditions was applied. Two types of resin-based composite materials indicated for the treatment of dental caries in the distal area were used: a micro-hybrid resin-based composite material (Gradia Direct posterior); packable resin-based composite material (Filtek P60). Metal alloy (Duceralloy C) was used for positive control.

For the preparation of an experimental model for tribological testing, standard metal plates were prepared carriers with dimensions - $50 \mathrm{~mm}$ x $50 \mathrm{~mm}$ and thickness of $3 \mathrm{~mm}$. Each of them was cut into 9 holes with a diameter of $10 \mathrm{~mm}$ and a depth of $1.5 \mathrm{~mm}$. The respective test material was applied to the openings. The retention of the composite test materials in the cut-out sockets of the metal plates was further reinforced by the metal primer (Metal Primer-2 GC Corporation Tokyo Japan) (fig. 1). 
Fig. 1. Metal primer application

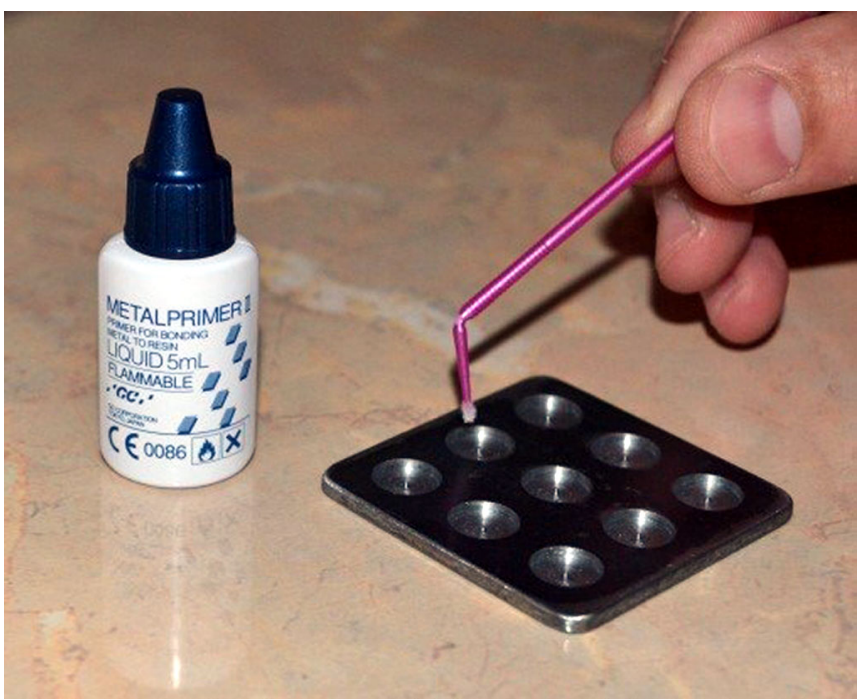

The composites' application and polymerization were carried out layer by layer using an experimental set-up proposed by us (fig. 2). The lamp (mini led Satelec, Switzerland) was fixed at a standard distance to the object - $10 \mathrm{~mm}$.

Fig. 2. Polymerization of the composites

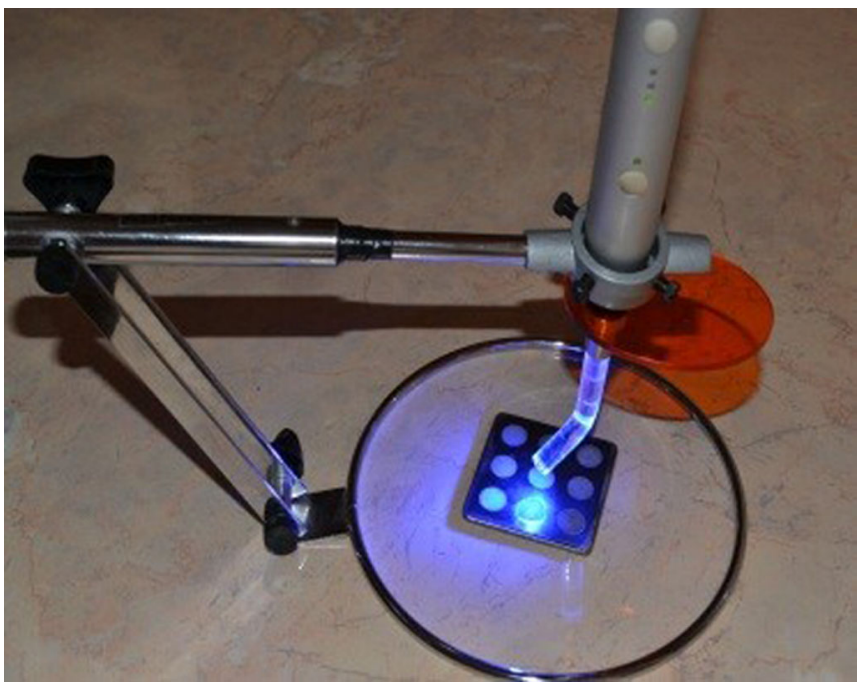

Positive control group specimens were made and cast from a metal alloy containing no nickel. The fixation of the metal alloy control tribological discs was performed using a prepared matrix form of additive silicone (Ormaplus, Major Italy). The parameters of the standard metal plate were used. Using an epoxy resin prepared according to the manufacturer's requirements metal test discs of the control study were fixed (fig. 3).
Fig. 3. Fixing of metal test discs of the control study

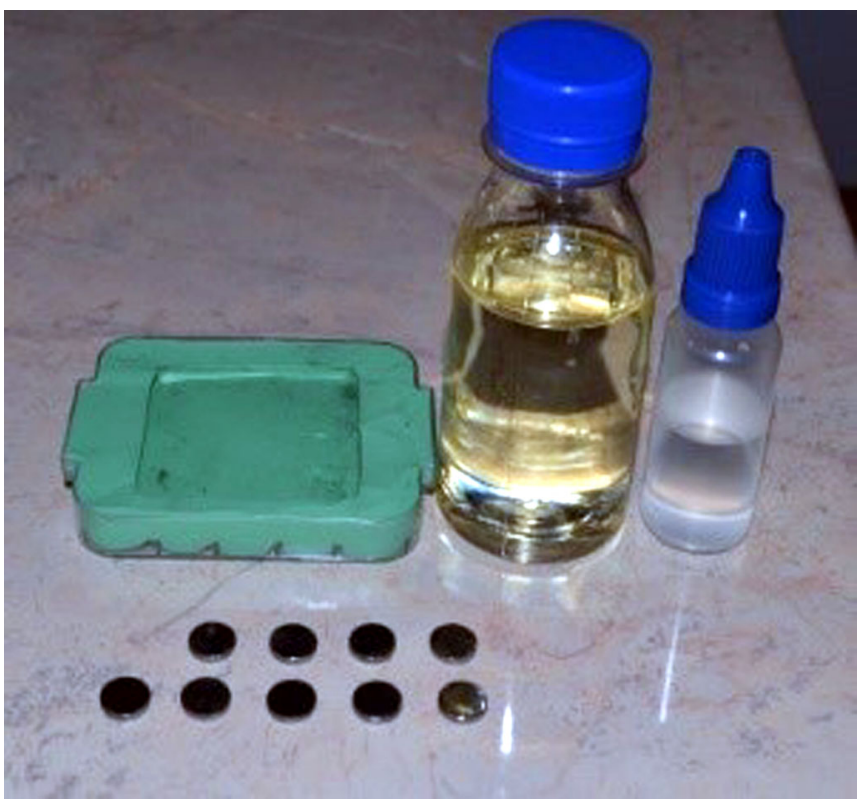

Total 18 test samples $(\mathrm{n}=9$ for each material) were subject to: micro scratch resistance test in $1 \mathrm{~N}, 5 \mathrm{~N}, 9 \mathrm{~N}$ mode; friction resistance "Ball-on-Flat" test at 120,000/240,000 cycles loaded on 50N (fig. 4).

Fig. 4. Design of the study

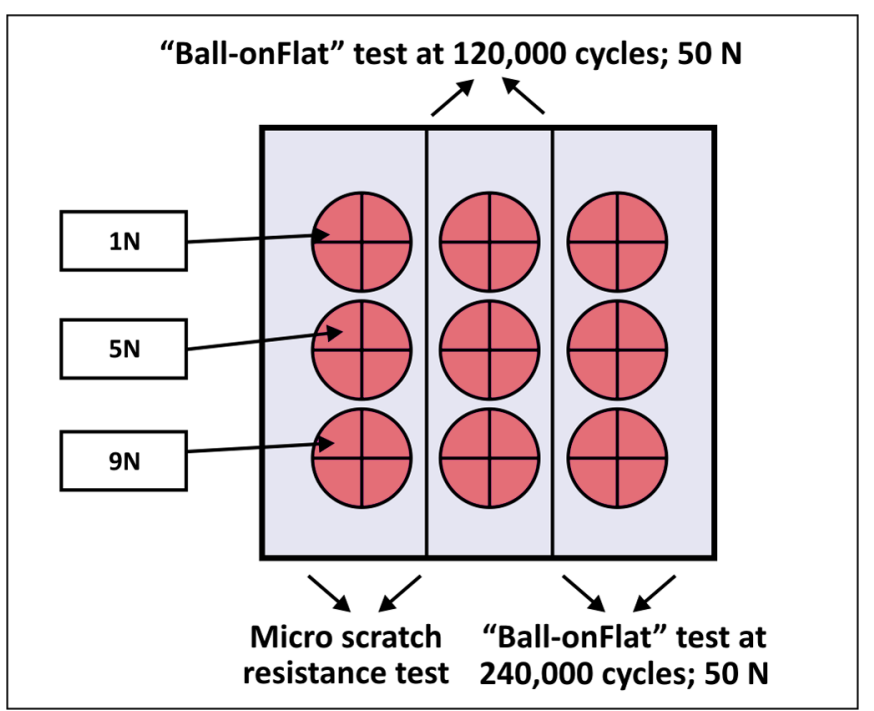

The testing device used in this study is UMT-2M (Bruker-CETR) (fig. 5). It is a universal modular apparatus for performing a wide range of macro and micro-mechanical and tribological tests on coatings (thin or thick, hard or soft) and bulk materials - ceramics, polymers, glass, composites, woven and paper. Works with loads ranging from $5 \mathrm{mN}-1000 \mathrm{~N}$; enables multiple sensors to be used and allows simultaneous measurement, visualization and realtime recording of deformations and forces while performing synchronized linear and rotary displacements across different axes using the synchronized linear or rotary drive. With a servo-control mechanism, a high precision of motion and load control were achieved. 
Fig. 5. UMT-2M (Bruker-CETR)

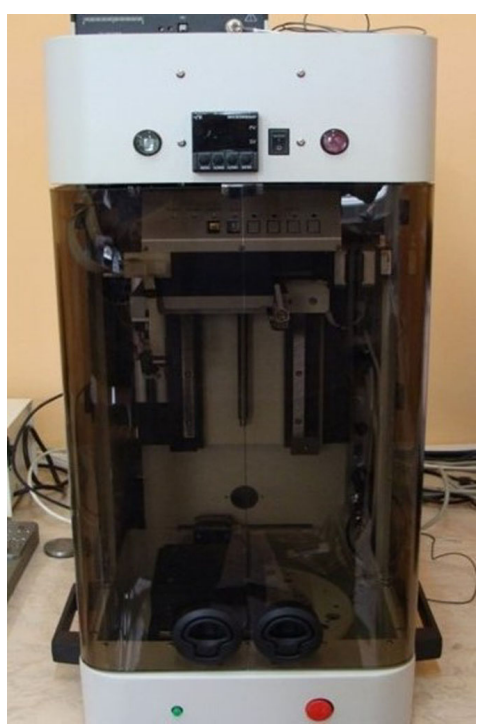

The micro-scratch test procedure and conditions were included a three-step cycle that performed multiple scratches with a $1 \mathrm{~mm}$ distance between each of them, and the length of each scratch was $5 \mathrm{~mm}$. The tests were performed according to ASTM standard G133-95.

Ball-on-flat wear tests were included the use of a 6.35 $\mathrm{mm}$ diameter chrome plated ball that was slid on the surface of the fixed, rigid piece (dental material in this case) under the action of a reciprocating motion of linear drive. The device was monitoring and recording the dynamic normal load, friction force and friction coefficient.

3D Zeta-20 (Zeta Instruments) optical profilometry device with a vertical $(Z)$ resolution of $<1 \mathrm{~nm}$, a field of view from $0.006 \mathrm{~mm}^{2}$ to $15 \mathrm{~mm}^{2}$, and a magnification of $5 \mathrm{x}, 20 \mathrm{x}, 50 \mathrm{x}$, and 100x was used for 3D profilometry.

\section{RESULTS:}

The results of the micro-scratch tests are represented by graphs - for each sample and each test (fig. 6).

Fig. 6. Graphic representation of micro scratch resistance test of A) Gradia Direct Posterior; B) Filtek P60 in 9 N mode
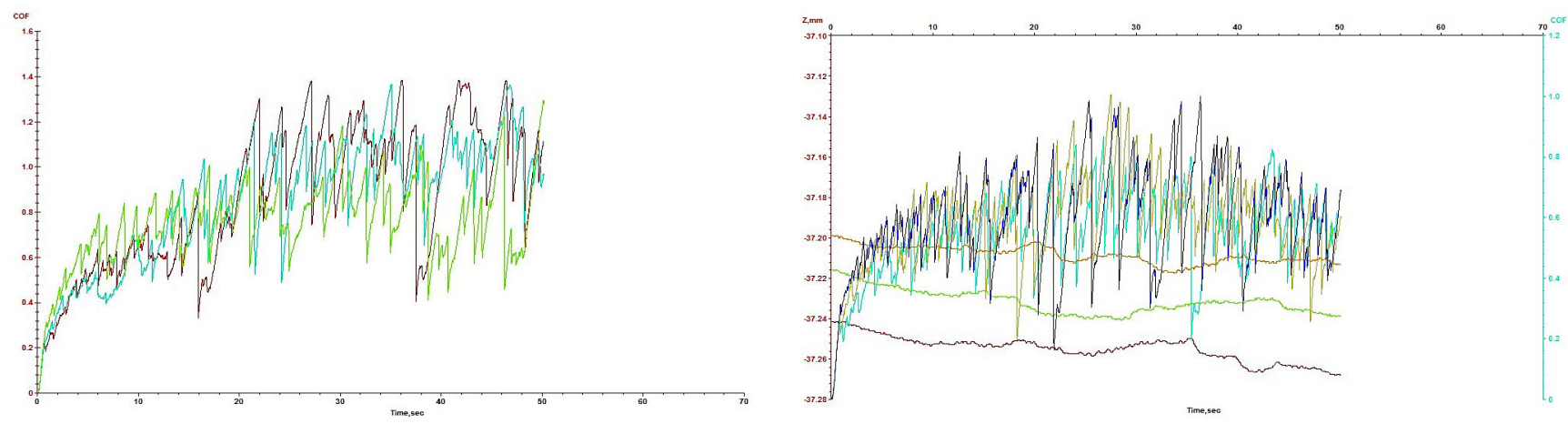

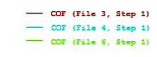
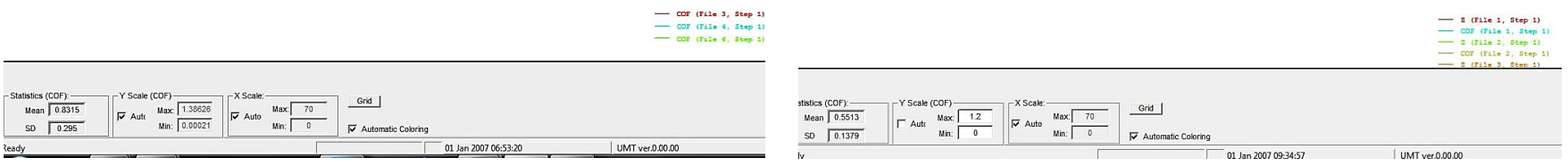

The averaged results of the micro-scratch tests are given in Table 1. When the maximum load was applied, Gradia Direct posterior had higher values of scratch depths $(40,23 \mu \mathrm{m})$ than Filtek P60 $(25,13 \mu \mathrm{m})$.

Table 1. Average values for the coefficient of friction and depth of micro-scratch depending on the applied load

\begin{tabular}{|c|c|c|c|c|}
\hline Samples & $\begin{array}{c}\text { Resin-based } \\
\text { composite material }\end{array}$ & Load $(\mathbf{N})$ & $\begin{array}{c}\text { Coefficient } \\
\text { of friction }\end{array}$ & $\begin{array}{c}\text { Depth of } \\
\text { micro-scratch }(\boldsymbol{\mu m})\end{array}$ \\
\hline \multirow{2}{*}{$\mathbf{1}$} & Gradia Direct Posterior & 1 & 0,4953 & 30,71 \\
& & 9 & 0,7599 & 28,21 \\
\hline \multirow{2}{*}{$\mathbf{2}$} & Filtek P60 & 1 & 0,8315 & 40,23 \\
\hline & & 5 & 0,4357 & 39,64 \\
& & 9 & 0,5074 & 30,75 \\
\hline
\end{tabular}

The results of the wear resistance tests for each sample as well as for each individual test and each individual cycle of each test are also presented graphically (fig. 7). 
Fig. 7. Graphic representation of "Ball-on-Flat" test at 240,000 cycles; 50 N A) Gradia Direct Posterior; B) Filtek P60
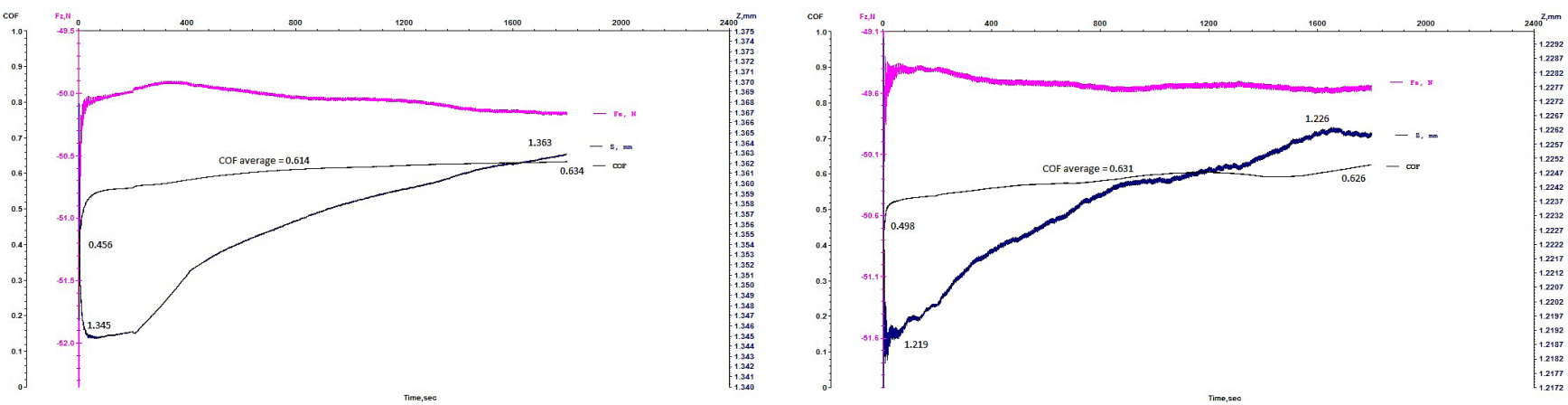

From Table 2, we can summarize that the micro-hybrid composite exhibited less wear resistance that decreased with increasing time and friction cycles (13 $\mu \mathrm{m}$ after $30 \mathrm{~min} / 120,000$ cycles; $18 \mu \mathrm{m}$ ether $60 \mathrm{~min} / 240,000$ cycles).

Table 2. Average values for the coefficient of friction and depth of friction for each of the two 30-minute wear cycles for each specimen

\begin{tabular}{|c|c|c|c|c|}
\hline Samples & $\begin{array}{c}\text { Resin-based } \\
\text { material }\end{array}$ & Load $(\mathbf{N})$ & $\begin{array}{l}\text { Coefficient } \\
\text { of friction }\end{array}$ & $\begin{array}{c}\text { Depth of } \\
\text { friction }(\mu \mathrm{m})\end{array}$ \\
\hline \multirow[t]{2}{*}{1} & \multirow{2}{*}{ Gradia Direct Posterior } & 50 & 0,5501 & 13 \\
\hline & & 50 & 0,614 & 18 \\
\hline \multirow[t]{2}{*}{2} & \multirow{2}{*}{ Filtek P60 } & 50 & 0,235 & 7 \\
\hline & & 50 & 0,631 & 7 \\
\hline
\end{tabular}

The examined surfaces of the test specimens were visualized by optical microscopy (fig. 8) after micro scratch and friction test and by 3D profilometry of all tested samples after 240,000 wear cycles (fig. 9 3D profilometry of Duceralloy C, fig. 10 3D profilometry of Gradia direct posterior, fig. 11 3D profilometry of Filtek P60).

Fig. 8. Optical microscopy

\section{before friction test}

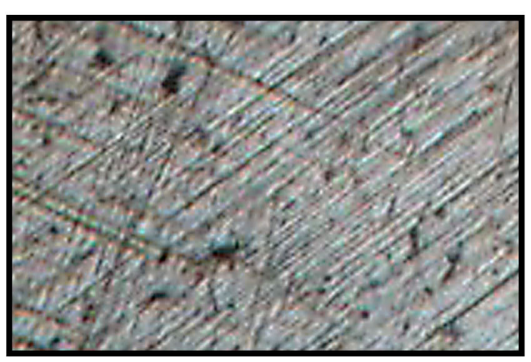

Ducerally C

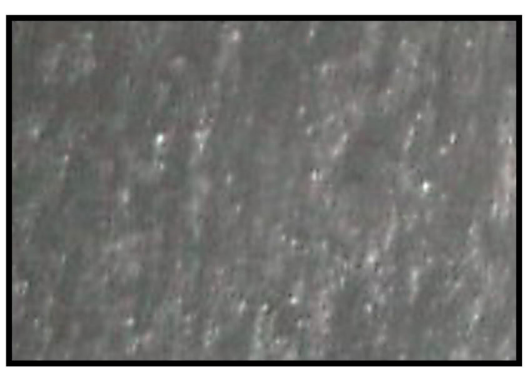

Gradia Direct posterior

\section{Optical microscopy} after 120000 wear cycles
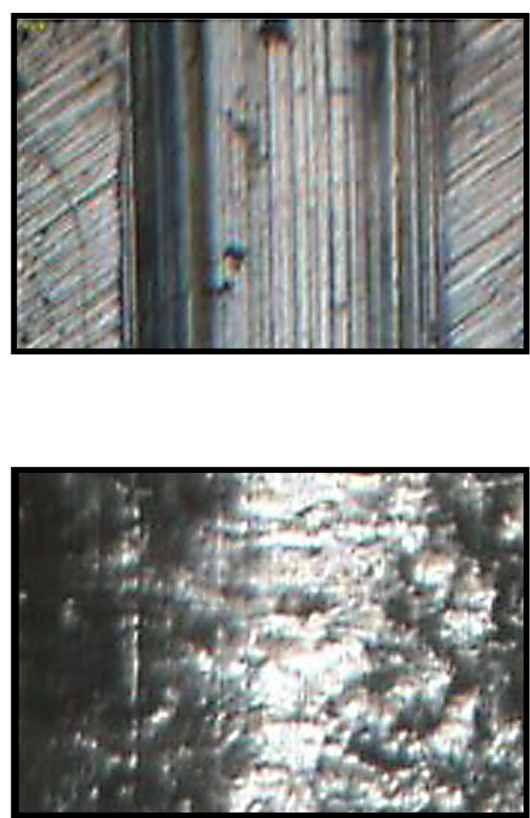

after 240000 wear cycles
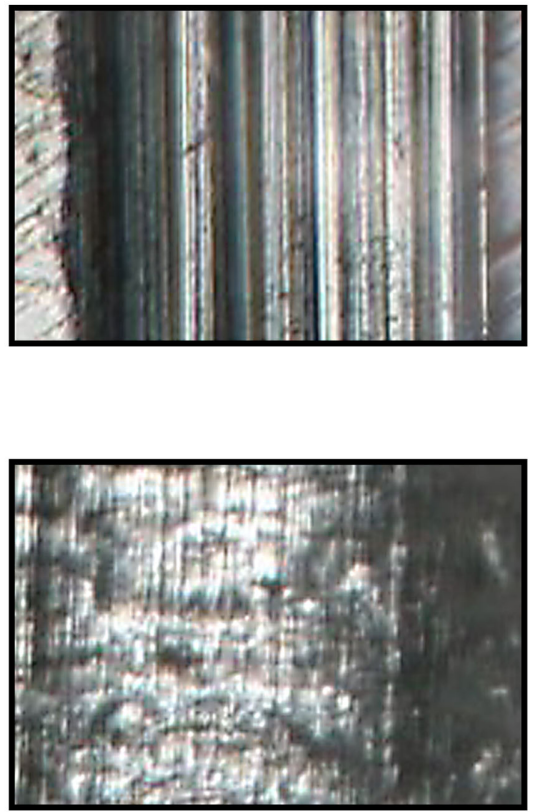

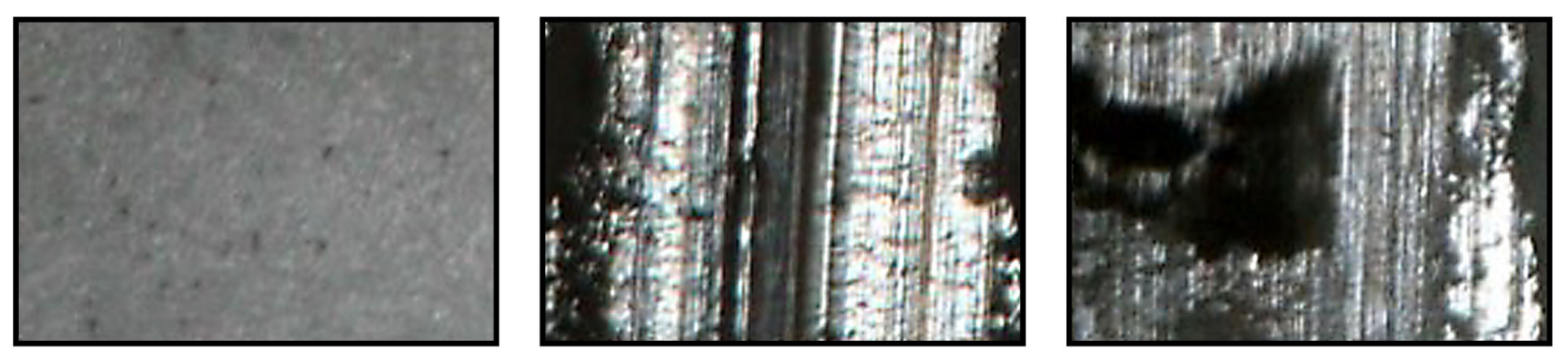

\section{Filtek P60}

Fig. 9. 3D profilometry of Duceralloy C
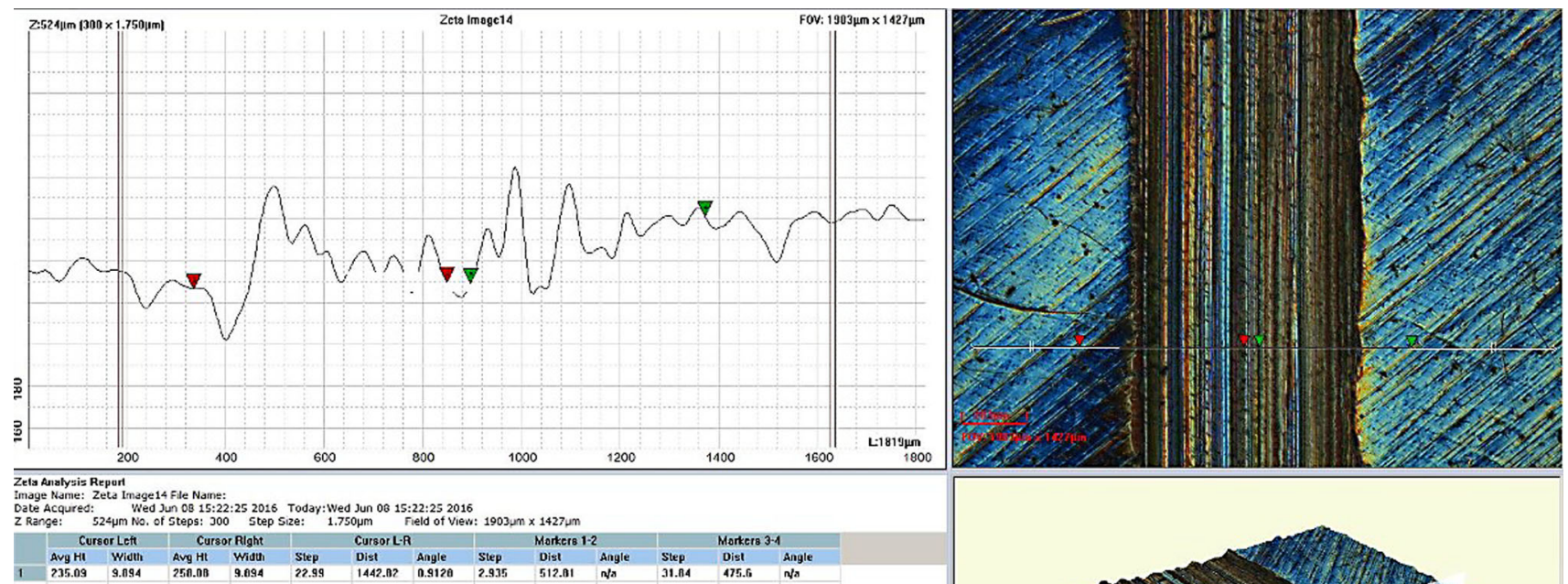

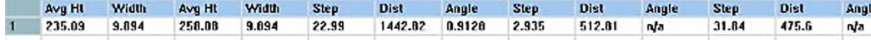

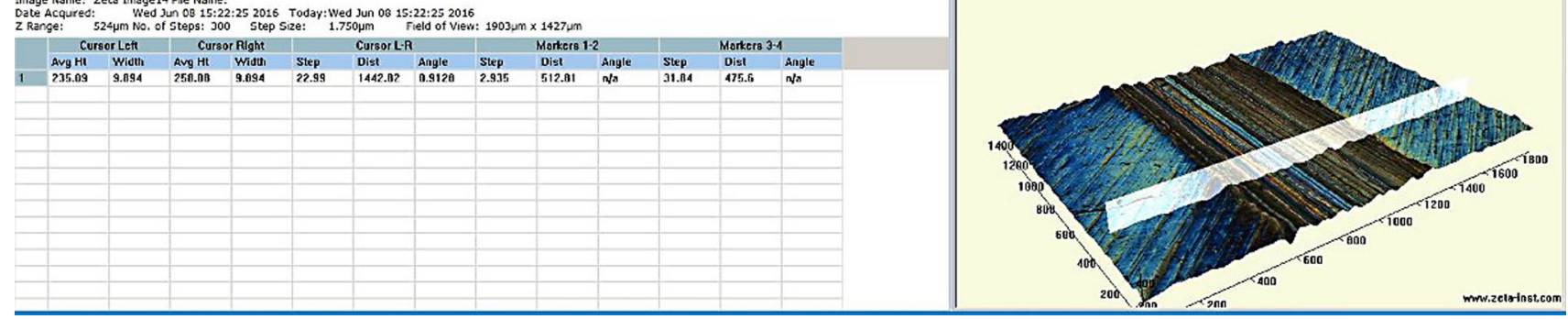

Fig. 10. 3D profilometry of Gradia direct posterior
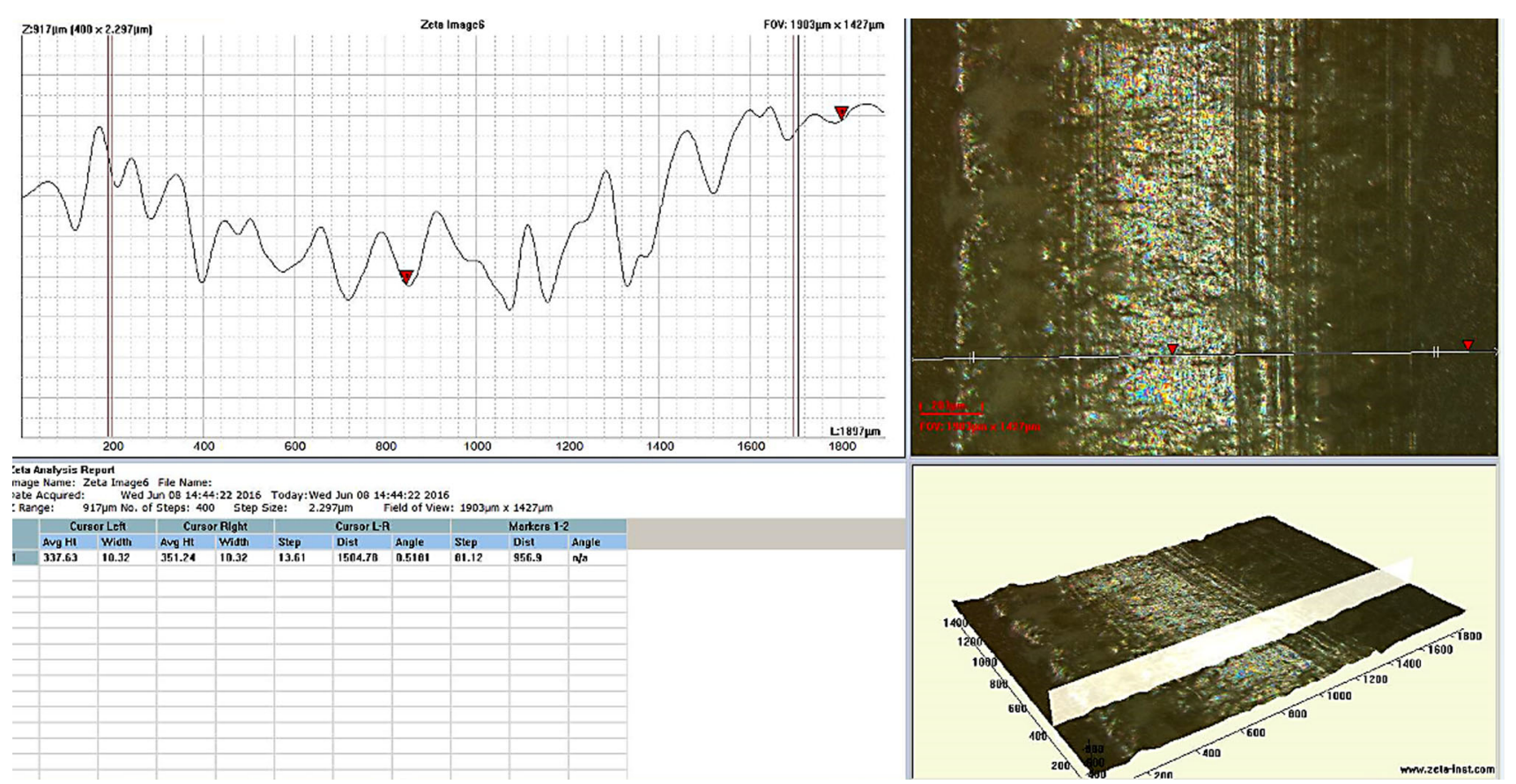
Fig. 11. 3D profilometry of Filtek P60
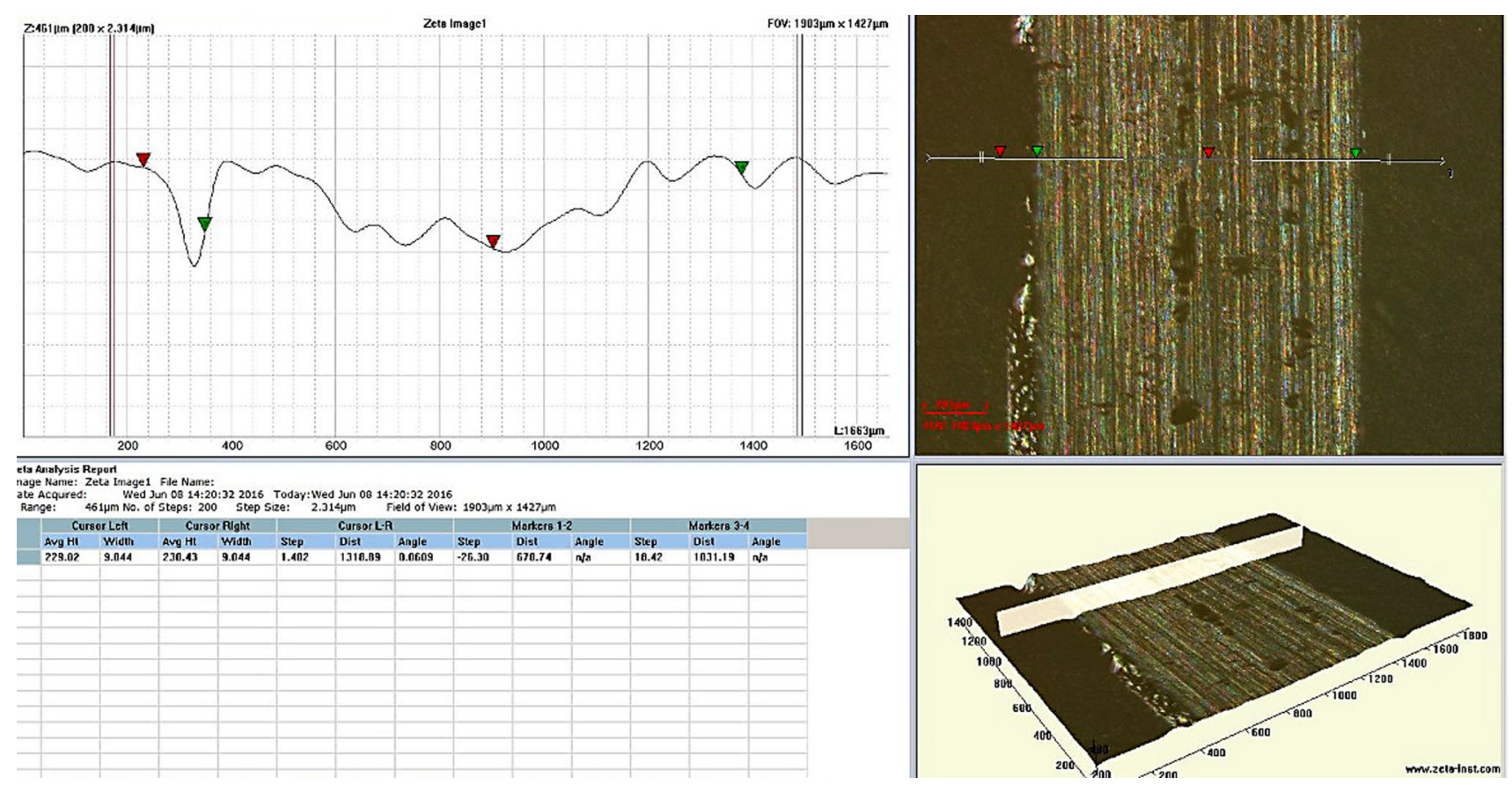

Due to the high hardness and homogeneous composition of the metal control, these samples exhibit a pronounced but uniform surface roughness. The surface roughness of the studied resin-based composite materials is less pronounced than the metallic control. They have multiple micropores. The logical explanation for this is the fact that they are made up of two different in nature phases - organic and inorganic, in which mechanical characteristics are significantly different. It is particularly pronounced for Filtek P60, while the Gradia Direct posterior as a micro-hybrid heterogeneous composite is characterized by the presence of an organic-inorganic filler. This significantly reduces the differences between the two phases.

\section{DISCUSSION:}

The surface relief of direct composite restorations is important for their durability as it reflects the interaction of restorative materials with the oral environment [4]. The results obtained are judged by the high roughness of the test specimens. We can conclude that in clinical conditions, the achievement of an optimal smoothness of obturations" surfaces is even more difficult. This affects their mechanical behavior, especially in conditions of extreme chewing forces. In laboratory tests on the wear resistance of resinbased composite materials by means of Two-body wear simulators, the condensable composites show no better wear resistance than conventional hybrid composites [5]. These results are confirmed by clinical studies [6].

No data are available to investigate the resistance to wear of dental materials with UMT-2M (Bruker-CETR).

Due to the specific measuring equipment and the differences in the methodology related to the testing of the tested samples and the modes (load force, number of cycles, duration) for the tests, the results obtained in the course of our study are not comparable to the cited laboratory tests in the scientific dental literature.

An analogy can be made with scientific research on the tribological characteristics of polymer-based materials that are not applied in the field of dentistry. Such studies describe scientists from the Institute of Mechanics and Biomechanics at the Bulgarian Academy of Sciences, who study different types of polypropylene and nanocomposites $[7,8]$. They use the test apparatus used for micro-scratch and friction resistance testing in our study. They found a difference in the coefficient of friction of the material tested from both types of test. Such a difference is also observed in our results for both types of resin-based composite materials. This shows a different degree of wear resistance on the surface and in the depth of the tested materials.

$3 \mathrm{D}$ profilometry is a fast, non-contacting and objective method that provides information on the topography and roughness of the surveyed objects. It can be used to obtain both topographic and quantitative data, which determines its wide application in a number of areas of medicine. The surface of both biological objects and various biocompatible materials is examined $[9,10]$.

In dental medicine, 3D profilometry is mainly used to study the abrasion resistance of hard dental tissues and various types of restorative materials - dental composites, glass-ionomer cement, dental ceramics [11]. 


\section{CONCLUSION:}

Of great importance for clinical practice is the conclusion that surface roughness and the lack of homogeneity of biomaterials can have a tremendous impact on their functional characteristics such as fatigue, wear-resistance, friction and corrosion resistance.

The clinical assessment of the durability of direct composite restorations in bruxing and clenching patients may cost years of clinical follow-ups. There are studies confirming the fact that in vitro simulation of wear is extremely valuable in the screening of new resin-based composite materials. Results in this field will clarify the mechanisms of wear and provide additional information on the expected changes in the studied materials in clinical practice.

\section{REFERENCES:}

1. Laluque J-F, Brocard D, d'Incau E. Understanding of Bruxism: Current knowledge and practice. 1st edition. Quintessence Publishing Co., Inc. January 1, 2018. pp.3-8. [Internet]

2. Lavigne G, Montplaisir J. Bruxism: epidemiology, diagnosis pathophysiology and pharmacology. $A d v$ Pain Res Therapy. 1995; 21:387-92.

3. Zhou ZR, Zheng J. Tribology of dental materials: a review. J Phys D: Appl Phys. 2008 May 13;41(11): 113001. [Crossref]

4. Ghinea R, Ugarte-Alvan L, Yebra A, Pecho OE, Paravina RD, Perez M, et al. Influence of surface roughness on the color of dental-resin composites. $J$ Zhejiang Univ Sci B. 2011 Jul;12(7): 552-62. [PubMed]

5. Turssi CP, Faraoni-Romano JJ, de Menezes M, Serra MC. Comparative study of the wear behavior of composites for posterior restorations. J Mater
Sci Mater Med. 2007;18:143-7.

6. Shi L, Wang X, Zhao Q, Zhang Y, Zhang L, Ren Y, et al. Evaluation of packable and conventional hybrid resin composites in Class I restorations: three-year results of a randomized, double-blind and controlled clinical trial. Oper Dent. 2010 Jan-Feb;35(1):11-9. [PubMed]

7. Borovanska I, Tsekov Yu, Angelov V, Ivanov E, Kotsilkova R, Djoumaliisky S. Tribological measurements of polypropylene nanocomposites by scratch and friction tests. Tribological Journal Bultrib. 2013; 3:226-35.

8. Petrova I, Ivanov E, Kotsilkova R, Tsekov Y, Angelov V. Applied study on mechanics of nanocomposites with carbon nanofillers. JTAM, Sofia. 2013; 43(3):67-76.

9. Almeida JC, Wacha A, Gomes PS,
Alves LC, Fernandes MH, Salvado IM, et al. A biocompatible hybrid material with simultaneous calcium and strontium release capability for bone tissue repair. Mater Sci Eng C Mater Biol Appl. 2016 May;62:429-38. [PubMed] [Crossref]

10. Lademann J, Vergou T, Darvin ME, Patzelt A, Meinke MC, Voit C, et al. Influence of Topical, Systemic and Combined Application of Antioxidants on the Barrier Properties of the Human Skin. Skin Pharmacol Physiol. 2016; 29(1):41-6. [PubMed] [Crossref]

11. Fleming GJ, Reilly E, Dowling $\mathrm{AH}$, Addison O. Data acquisition variability using profilometry to produce accurate mean total volumetric wear and mean maximum wear depth measurements for the OHSU oral wear simulator. Dent Mater. 2016 Aug;32(8): e176-84. [PubMed] [Crossref]

Please cite this article as: Aleksandrova V, Manchorova N, Aleksandrov S. Tribological tests of Resin-Based Composite Materials: a design study. J of IMAB. 2021 Apr-Jun;27(2):3700-3706. DOI: https://doi.org/10.5272/jimab.2021272.3700

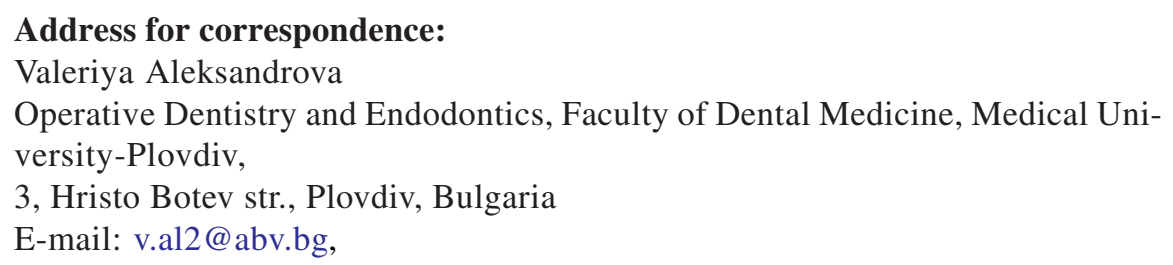

